\title{
Solving economic dispatch and unit commitment problem in smart grid system using eagle strategy based crow search algorithm
}

Rachid Habachi, Achraf Touil, Abdellah Boulal, Abdelkabir Charkaoui, Abdelwahed Echchatbi

Industrial Management and Innovation, The Faculty of Sciences and Technology, Hassan 1st University, Morocco

\begin{tabular}{|c|c|}
\hline Article Info & ABSTRACT \\
\hline Article history: & The economic dispatch problem of power plays a very important role in the \\
\hline Received Nov 20, 2018 & $\begin{array}{l}\text { exploitation of electro-energy systems to judiciously distribute power } \\
\text { generated by all plants. The Unit commitment problem (UCP) is mainly }\end{array}$ \\
\hline Revised Jan 21, 2019 & finding the minimum cost schedule to a set of generators by turning each one \\
\hline Accepted Feb 27, 2019 & $\begin{array}{l}\text { either on or off over a given time horizon to meet the demand load and } \\
\text { satisfy different operational constraints. This research article integrates the }\end{array}$ \\
\hline Keywords: & $\begin{array}{l}\text { crow search algorithm (CSA) as a local optimizer of Eagle strategy (ES) to } \\
\text { solve economic dispatch and unit commitment problem in smart grid system. }\end{array}$ \\
\hline
\end{tabular}

Crow search algorithm (CSA)

Eagle strategy (ES)

Economic dispatch problem

Smart grid system

Unit commitment problem

Copyright $(0) 2019$ Institute of Advanced Engineering and Science. All rights reserved.

\section{Corresponding Author:}

Rachid Habachi,

Laboratory of Mechanical Engineering,

Industrial Management and Innovation,

Faculty of Sciences and Technology,

Hassan 1st University, PO Box 577, Settat, Morocco.

Email: habachirachid@gmail.com

\section{INTRODUCTION}

Smart grids are a set of technologies, concepts and approaches, allowing the integration the generation, transmission, distribution and use into one internet by full use of advanced sensor measurement technology, communications technology, information technology, computer technology, control technology, new energy technologies [1]. However, Smart Grid uses digital technology to control grid and choosing the best mode of power distribution to reduce energy consumption, reduce costs, increase reliability and also increase transparency in the network. Therefore, the system intelligent will have will have a significant impact in the fields of finance and economics of the power industry [2]. Although, the traditional network is a one-way network in which the electrical energy produced in power plants is channeled to consumers without information to create an automated and distributed network of advanced power supplies.

The unit commitment problem plays a significant role in optimizing the cost of generating electrical power by planning production units based on the allocation of the production cost of each unit and the actual output power [3]. They involves scheduling the on/off states of generating units to minimize the operating cost for a given time horizon. The committed units must meet the systems fore-casted demand and spinning reserve requirement at minimum operating cost, subject to a large set of operating constraints.

The UC problem, one of the most important tasks in short-term operation planning of modern power systems, has a significant influence on the secure and economic operation of power systems [4]. Optimal commitment scheduling cannot only save millions of dollars for power companies; it also ensures system reliability by maintaining the proper spinning reserve. 
ED is also applied in the integrated system for scheduling power plants. A few methods have been published to solve the ED problem and Optimal Power Flow (OPF). Researchers have published a few methods to solve ED and OPF problems. Direct method is accurate and very simple but limited by the quadratic objective function [5].

The economic dispatch (ED) is one of the power management tools that are used to determine real power output of thermal generating units to meet required load demand. The ED results in minimum fuel generation cost, minimum transmission power loss while satisfying all units, as well as system constraints [6], [7].

The rise of energy demand and insufficient of energy resources are required for quality and secured dispatch [8]. A well-coordinated and optimized power system operation helps in satisfying Economic Dispatch (ED) among users of power networks. Hence, studies need to be conducted in order to analyze and develop new tools so that the optimization issues in ED could be overcome. Basically, the principal objective of load dispatch is to minimize the total fuel cost while satisfying the requirements of some important operational parameters. In today's environment, efficient load dispatch requires not only to schedule the power generation at the least cost but also to consider other performance factors to be optimized in power flow over the networks. The obligation of social attentions has influenced the reduction of energy conservation and pollution emission produced by power plants [9].

Facing the electric bulimia experienced by the world and as an urgent and efficient solution is sought, it is essential to optimize the cost of producing electricity. As such, tiny cuts costs conceal huge potential savings, this is part of this paper, and we look at the overall optimization purposes known economic load distribution (OPF) or economic dispatch (ED) [10].

The ED is a static problem is to say we must define at a given powers generated by each power plant to power a load as economically as possible. To solve this problem the optimization methods are used.

Conventional optimization techniques [11], [12]. Have long been applied to solve the ED problem such as Quadratic Programming [13], [14]. Linear programming [15] sequential approach with a matrix framework (SAMF) [16]. Modified Lambda-iteration method [17], Newton Raphson and Lagrangian multiplier (LM) algorithms [18], in the real-design cases, the number of decision variables (i.e. power units) of the ED area are very large. The objective criterion to be minimized could also have too many local minimum which might not lead to the minimum cost and the best generation schedule of power system units. Therefore, efficient search algorithms are needed.

Nature-inspired metaheuristic search algorithms gain popularity due to their promising performance on solving many real-world optimization problems which are complex, nonlinear and multi-model. In the past two decades, the literature of metaheuristic search has expanded extensively.

Some of the well-known metaheuristic approaches are Genetic Algorithms [19], Genetic Programming [20], [22], Particle Swarm Optimization [23], [24], Simulated Annealing [25], Artificial Bee Colony (ABC) [26], Cuckoo Search [27-28], crow search algorithm [29].

The rest of this paper is organized as follows. Section 2 contains the problem formulation of the ED and UCP. Section 3 briefly presents the basics of ES and CSA. Section 4 proposes the binary eagle strategy based crow search algorithm to solve Economic dispatch and UCP. Section 5 provides the computational results. Finally, Section 6 outlines the conclusions.

\section{PROBLEM FORMULATION}

The scheduling problem of generators solved ideally by acquiring exhaustive trial of all solutions and best solution is chosen amongst them. All possible units supplying a load and reserve requirements would be tested and choose the optimal solution that have the minimum operating cost [30] The generating units' output power with system constraints over a time period $\mathrm{T}$ and startup/shut down times at each step required to scheduling problem of generator. The running cost significant term of a thermal unit is the output power of the committed units [31] the fuel cost, FCi is represented in a quadratic form of output power in a time interval given in (1)

$$
\mathrm{F}_{\mathrm{T}}=\sum_{\mathrm{i}=1}^{\mathrm{N}} \mathrm{F}_{\mathrm{i}}\left(\mathrm{P}_{\mathrm{i}}\right)=\sum_{\mathrm{i}=1}^{\mathrm{N}} \mathrm{a}_{\mathrm{i}}+\mathrm{b}_{\mathrm{i}} \mathrm{P}_{\mathrm{i}}+\mathrm{c}_{\mathrm{i}} \mathrm{P}_{\mathrm{i}}^{2}
$$

Where $a, b, c$ are cost coefficients of unit and $p$ is the unit generating power. The start-up cost (SC) calculation depends on the treatment strategy for a thermal unit during down time periods and an exponentialcost curve shown in (2) is its representation. where $\sigma, \delta, \tau$ is the hot startup cost, the cold startup cost and the cooling time unit constant and $\mathrm{T}$, is the time at which the unit has been turned off so The total production cost, $\mathrm{F}$ is the sum of the operating, startup and shut down costs for all the units illustrated in (3) 


$$
\begin{aligned}
& \mathrm{SCi}=\sigma \mathrm{i}+\delta \mathrm{i} *\left\{1-\exp \left(-\frac{\mathrm{Toff}}{\tau \mathrm{i}}\right)\right\} \\
& \mathrm{F}_{\mathrm{T}}=\sum_{\mathrm{h}=1}^{\mathrm{T}} \sum_{\mathrm{i}=1}^{\mathrm{N}} \mathrm{FCi}, \mathrm{t}+\mathrm{SCi}, \mathrm{t}+\mathrm{SDi}, \mathrm{t}
\end{aligned}
$$

Where $\mathrm{N}$ is the number of generators and different load demands number is $\mathrm{T}$ at estimated commitment, SD is the shutdown cost.

Some constraints should be taken into consideration to minimize $\mathrm{F}$ as:

(i) Power balance equation is given by (4):

$$
\sum_{\mathrm{i}=1}^{\mathrm{N}} \mathrm{Pi} \mathrm{Ui}=\left(\mathrm{P}_{\mathrm{D}}+\mathrm{P}_{\mathrm{L}}\right)
$$

Where PD is the load demand and PL is the power loss of the system.

(ii) The hourly spinning reserve (R) is given by (5):

$$
\sum_{\mathrm{i}=1}^{\mathrm{N}} \mathrm{Pi}, \max \mathrm{Ui}=\left(\mathrm{P}_{\mathrm{D}}+\mathrm{P}_{\mathrm{L}}\right)+\mathrm{R}
$$

(iii) Unit rated minimum and maximum capacities as in (6):

$$
\mathrm{P}_{\text {i.min }} \leq \mathrm{P}_{\mathrm{i}} \leq \mathrm{P}_{\text {i.max }}
$$

The initial conditions of each unit and minimum up /down (MUT/MDT) time limits of units are given by (7) and (8) respectively.

$$
\begin{aligned}
& \left(\mathrm{T}_{\mathrm{t}-1, \mathrm{i}}^{\mathrm{on}}-\mathrm{MUTi}\right) *\left(\mathrm{U}_{\mathrm{t}-1, \mathrm{i}}-\mathrm{U}_{\mathrm{t}, \mathrm{i}}\right) \geq 0 \\
& \left(\mathrm{~T}_{\mathrm{t}-1, \mathrm{i}}^{\text {off }}-\mathrm{MUTi}\right) *\left(\mathrm{U}_{\mathrm{t}-1, \mathrm{i}}-\mathrm{U}_{\mathrm{t}, \mathrm{i}}\right) \geq 0
\end{aligned}
$$

Where the unit off/on time is Toff/Ton the and the unit off /on [0, 1] status is Ut,i. the enhancement of ELD problem is represented by (9):

$$
\mathrm{F}_{\mathrm{T}}=\sum_{\mathrm{i}=1}^{\mathrm{N}} \mathrm{F}_{\mathrm{i}}\left(\mathrm{P}_{\mathrm{i}}\right) \sum_{\mathrm{i}=1}^{\mathrm{N}} \mathrm{a}_{\mathrm{i}}+\mathrm{b}_{\mathrm{i}} \mathrm{P}_{\mathrm{i}}+\mathrm{c}_{\mathrm{i}} \mathrm{P}_{\mathrm{i}}^{2}
$$

Subject to the equality and inequality contraints are given by (10) and (11) respectively.

$$
\begin{aligned}
& \sum_{\mathrm{i}=1}^{\mathrm{N}} \mathrm{Pi}=\left(\mathrm{P}_{\mathrm{D}}+\mathrm{P}_{\mathrm{L}}\right) \\
& \mathrm{P}_{\text {i.min }} \leq \mathrm{P}_{\mathrm{i}} \leq \mathrm{P}_{\text {i.max }}
\end{aligned}
$$

\section{OVERVIEW OF EAGLE STRATEGY AND CROW SEARCH ALGORITHM}

\subsection{Egale Strategy}

Eagle strategy is a two-stage optimization strategy was presented by [32]. This algorithm mimics behavior of eagles in nature. In fact, eagles use two different components to search for their prey. The first one is a random search performed by flying freely and the second one is an intensive search to catch prey when they see them. In this two-stage strategy, the first stage explores the search space globally by using a Levy flight: if it finds a promising solution, then an intensive local search is employed using more efficient local optimizer, such as hill-climbing and the down-hill simplex method. Then, the two-stage process commences another time with new global exploration, followed by local search in a new area. One of the remarkable advantages of such a combination is to use a parallel balance between global search (which is generally slow) and a rapid local search. There i s another advantage that is called a methodology or strategy, not an algorithm. In fact, there are different algorithms that can be used at different times and stages during iterations. The main steps of the ES are outlined in Algorithm 1. 


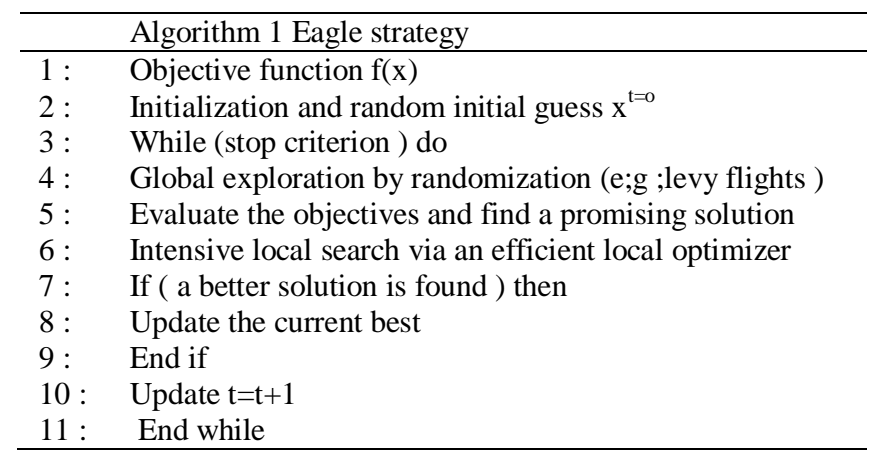

\subsection{Crow Search Algorithm}

The crow search algorithm (CSA) is a new population-based stochastic search algorithm recently proposed by [33]. The CSA is a newly developed optimization technique to solve complex engineering optimization problems [34-35]. It is inspired by the intelligent behavior of crows.The principles ofCSA are listed as follows [33]:

Crows live in the form of the flock.

Crows memorize the position of their hiding places.

Crows follow each other to commit thievery.

Crows protect their caches from being pilfered through probability.

Following the above assumptions, the core mechanism of the CSA consists of three basic phases, namely initialization; generate a new position, and updating the memory of crows. At first, the initial population of crows represented by $\mathrm{n}$ dimension is randomly generated. At iteration $\mathrm{t}$, the position of crow is specified by $\mathrm{x}^{\mathrm{i}, \mathrm{t}}=\left[\mathrm{x}_{1}^{\mathrm{i}, \mathrm{t}}, \mathrm{x}_{2}^{\mathrm{i}, \mathrm{t}}, \ldots \ldots, \mathrm{x}_{\mathrm{n}}^{\mathrm{i}, \mathrm{t}}\right]$ and it is assumed that this crow has memorized its best experience thus far in its memory $\mathrm{m}^{\mathrm{i}, \mathrm{t}}=\left[\mathrm{m}_{\mathrm{m} 1}^{\mathrm{i}, \mathrm{t}}, \mathrm{m}_{2}^{\mathrm{i}, \mathrm{t}}, \ldots \ldots, \mathrm{m}_{\mathrm{n}}^{\mathrm{i}, \mathrm{t}}\right]$ To generate a new position, crow $\mathrm{i}$ select randomly a crow $\mathrm{j}$, for example, from the population and attempts to follow it to find the position of its hiding place (mj ). In this case, according to a parameter named awareness probability (AP), two states may happen:

State 1: Crow $\mathrm{j}$ does not know that crow $\mathrm{i}$ is following it. As a result, the crow $\mathrm{i}$ will determine the hiding place of crow $\mathrm{j}$.

State 2: Crow $\mathrm{j}$ knows that crow $\mathrm{j}$ is following it. As a result, to protect its cache from being pilfered, the crow $\mathrm{j}$ will fool crow $\mathrm{i}$ by going to another position whitin the search space.

According to States 1 and 2, the position of the crows is updated as follows:

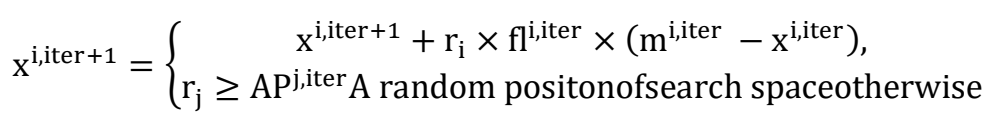

Where rj is a uniformly distributed fuzzy number from $[0 ; 1]$ and $\mathrm{AP}^{\mathrm{j}}$,iter denotes the awareness probability of crow $\mathrm{j}$ at iteration iter. Finally, the crows update their memory as follows:

$$
\mathrm{m}^{\mathrm{i}, \text { iter }+1}=\left\{\begin{array}{c}
\mathrm{x}^{\mathrm{i}, \text { iter }+1}, \text { if } \mathrm{f}\left(\mathrm{x}^{\mathrm{i}, \mathrm{iter}}\right) \text { is better than } \mathrm{f}\left(\mathrm{m}^{\mathrm{i}, \text { iter }}\right) \\
\mathrm{m}^{\mathrm{i}, \text { iter }}, \text { otherwise }
\end{array}\right.
$$

Where $\mathrm{f}(-\quad)$ denotes the objective function value. It is seen that if the fitness function value of the new position of a crow is better than the fitness function value of the memorized position, the crow updates its memory by the new position. The above process is repeated until a given termination criterion (itermax) is met. Finally, the best solution of the memories is returned as the optimal solution found by the CSA. The main steps of the CSA are outlined in Algorithm 2: 


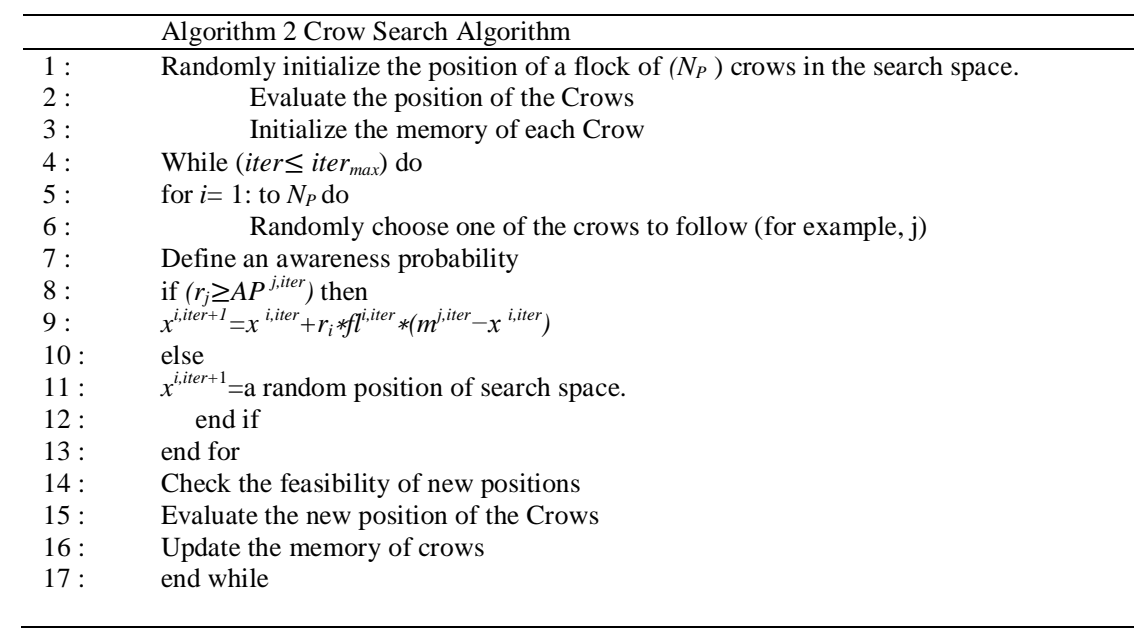

\section{BINARY EAGLE STRATEGY BASED CROW SEARCH ALGORITHM FOR ED AND UC}

The binary ES-CSA is used to optimise the unit-scheduling problem in the first step, and the Lambda-iteration method [36] is used to solve the economic load dispatch problem in the second step. These two steps run iteratively until the algorithm meets the stopping criterion. Optimising the first sub problem of unit-scheduling is more difficult than the other sub-problem of ELD. So this paper mainly discusses how to model BESCSA for the first sub-problem, and the second sub-problem is solved by the traditional Lambda-iteration method. These two sub-problems are optimised iteratively until the algorithm meets the stopping criterion. The (13) are transfer from continues to binary space using the following equations :

$$
x^{i, i t e r}=\left\{\begin{array}{lr}
1 & \text { if } s\left(x^{i, i t e r}\right) \geq \operatorname{rand}() \\
0 & \text { if otherwise }
\end{array}\right.
$$

Where $\mathrm{s}\left(\mathrm{x}^{\mathrm{i}, \mathrm{iter}}\right)=\frac{1}{\mathrm{y}}, \mathrm{y}=1+\mathrm{e}^{-\mathrm{x}^{\mathrm{i}, \text { iter }}}$ and $\operatorname{rand}()$ is a random number from uniform distribution $[0 ; 1]$ and $\mathrm{x}^{\mathrm{i}, \text { iter }}$ is the updated binary position at iter iteration.

\subsection{Solution Representation and Initialization}

Before using the proposed binary ES-CSA to solve UCP, the representation of a crow must be defined. A crow is also called an individual. Hence, we defined each unit on/off (or 1/0) status as a gene, all available unit status at each hour make up a sub-chromosome, and there are $\mathrm{H}$ sub-chromosomes over the time horizon $\mathrm{H}$ comprising an individual. An individual would display the unit commitment schedule over the time horizon $\mathrm{H}$. The on/off schedule of the units is stored as an integer-matrix $\mathrm{U}$ with dimension $\mathrm{N} G \mathrm{H}$. A matrix representation of an individual in the population is shown as follows:

$$
U=\left[\begin{array}{ccccc}
u_{1}^{1} & u_{1}^{2} & u_{1}^{3} & \ldots & u_{1}^{H} \\
u_{2}^{1} & u_{2}^{2} & u_{2}^{3} & \ldots & u_{2}^{H} \\
\vdots & \vdots & \vdots & \ddots & \vdots \\
u_{N}^{1} & u_{N}^{2} & u_{N}^{3} & \ldots & u_{N}^{H}
\end{array}\right]
$$

Where uhi is unit on/off status of unit $\mathrm{i}$ at time $\mathrm{h}$ (uhi $=1=0$ for on/off).

In the initialization process, a set of individuals is created at random. For the complete $\mathrm{N} \mathrm{P}$ population, the candidate solution of each individual $\mathrm{Uj} ;(\mathrm{j}=1 ; 2 ;:: ; \mathrm{N} \mathrm{P})$ is randomly initialized. The position uhi of each crow $\mathrm{Uj}$ is generated using a uniform distributed random function, which generates either 0 or 1 and they are equally likely.

\subsection{Generate New Solutions}

As mentioned above, the ES is a two-stage strategy, and we can use different algorithms at different stages. In the first stage, ES uses the so-called Levy flights, which represent a kind of non-Gaussian stochastic process whose step sizes are distributed based on a Levy stable distribution to generate new solutions. When a new solution is produced, the following Levy flight is applied: 


$$
x^{i, i t e r+1}=x^{i, i t e r}+\alpha \oplus \operatorname{Levy}(\lambda)
$$

Here, is the step size that is relevant to the scales of the problem. The product means entry-wise multiplications. Levy flights essentially provide a random walk while their random steps are drawn from a Levy distribution for large steps:

$$
\operatorname{Levy}(\lambda)=u=t^{-\lambda}, 1 \leq \lambda \leq 3
$$

In this paper, we will use the Mantegna algorithm [37], which is one of the most efficient algorithms used to implement Levy flights. We assume that Levy $(\lambda)=$ s, so the formula can also be described as follows: By using Mantegna's algorithm [38], the step length s can be calculated as follows:

$$
\mathrm{x}^{\mathrm{i}, \text { iter+1 }}=\mathrm{x}^{\mathrm{i}, \text { iter }}+\alpha \oplus \mathrm{s}
$$

By using Mantegna's algorithm [26], the step length s can be calculated as follows:

$$
\mathrm{s}=\frac{\mu}{|\mathrm{v}|} 1 / \beta
$$

Where $\mu$ and $v$ draw from the normal ditrutions respectively. that is : $\mu \sim \mathrm{N}\left(0, \sigma_{\mathrm{u}}^{2}\right), v \sim \mathrm{N}\left(0, \sigma_{v}^{2}\right)$, and $\sigma_{\mathrm{v}}, \sigma_{\mathrm{u}}$, are calculated as follows $\left(\frac{\Gamma(1+\beta) \cdot \sin \left(\frac{\pi \beta}{2}\right)}{\Gamma\left(\frac{\beta+1}{2}\right) \cdot \beta \cdot 2^{\left(\frac{1-\beta}{2}\right)}}\right)^{\frac{1}{\beta}}, \sigma_{\mathrm{v}},=1$ Here $0 \leq \beta \leq 2$ and (:) is theGamma function. For the second stage, we can use the crow search algorithm (CSA) for the intensive local search. We know the CSA is a global search algorithm, but it can easily be tuned to do an efficient local search by limiting new solutions locally around the most promising region. As mentioned above, in the CSA, there are two specific parameters: awareness probability (AP) and flight length (f 1). Small values of AP intensify the local search, while large values result in a global search. Hence, the CSA can easily be used as a local optimizer by setting the awareness probability to very small values, and for good performance, we choose the flight length $\mathrm{f} l=2$. Such a combination may produce better results than those using pure CSA.

In UCP, binary numbers 0 and 1 are used to indicate the unit status (i.e., OFF or ON). The proposed startegy is essentially a real-coded algorithm, and therefore some modifications are needed to enable it to deal with the binary variable (i.e., 0 and 1) optimization problem.

\section{RESULTS AND DISCUSSION}

In this section, we present the results obtained based on ES-CSA for solving the economic dispatch problem and unit commitment problem and compare this results with the CM (Conventional Method) [17] and Particle Swarm Optimization [39]. A 10 unit's power unit system to explore our idea on using ES-CSA to find the optimal set of power generation of the system. ES-CSA will be used in this paper to solve the problem of economic dispatch and unit commitment. The programs are developed in MATLAB 7.9 environment.

The adopted system is expected to produce demand power of $1500 \mathrm{MW}$. The tuning parameters for ESCSA are given in Table 1; the Table 2 shows the cost coefficient of the 10 generators, under study, while the matrix is the loss coefficient matrix of the 10units power system. the generating unit data of the test system are given in Table 3 From the results of Table 4, we notice that ES-CSA give us the same production cost, and CM gives a slightly lower cost of $\$ 0.7 / \mathrm{h}$, ES-CSA gives us a good production cost and good accuracy. In the meantime, we examine the variation in the total fuel cost of test system with evolutionary generation numbers. For differenttest systems, the convergence processes of the best solution in the 30 trials are listed in Figures 1 and 2. From Figure 1, it is easy to see the ES-CSA has satisfactory con-vergence and the algorithm escaped from the local optima at thelater iterations. It proved that the stochastic searching mechanism of ES-CSA, which is conducted by gravitational forces among agents, is efficient. And the proposed mutation strategies improved theperformance of ES-CSA.

In Figure 2, we show the convergence of the metaheuristic search process based on ES-CSA in both the best and average cases. To see the difference between our new approach and another known method, we will compare the production cost found by ES-CSA to that found by PSO [40]. 
In this case, we will test the operation of ES-CSA. For this, we will use a simple network of 26 nodes with 10 production units. The total demand of the network is equal to $1500 \mathrm{MW}$ and loss coefficients are as follows:

$$
\mathrm{B}_{\mathrm{mn}}=10^{-5}\left[\begin{array}{llllllllll}
4.9 & 1.4 & 1.5 & 1.5 & 1.6 & 1.7 & 1.7 & 1.8 & 1.9 & 2.0 \\
1.4 & 4.5 & 1.6 & 1.6 & 1.7 & 1.5 & 1.5 & 1.6 & 1.8 & 1.8 \\
1.5 & 1.6 & 3.9 & 1.0 & 1.2 & 1.2 & 1.4 & 1.4 & 1.6 & 1.6 \\
1.5 & 1.6 & 1.0 & 4.0 & 1.4 & 1.0 & 1.1 & 1.2 & 1.4 & 1.5 \\
1.6 & 1.7 & 1.2 & 1.4 & 3.5 & 1.1 & 1.3 & 1.3 & 1.5 & 1.6 \\
1.7 & 1.5 & 1.2 & 1.0 & 1.1 & 3.6 & 1.2 & 1.2 & 1.4 & 1.5 \\
1.7 & 1.5 & 1.4 & 1.1 & 1.3 & 1.2 & 3.8 & 1.6 & 1.8 & 1.8 \\
1.8 & 1.6 & 1.4 & 1.2 & 1.3 & 1.2 & 1.6 & 4.0 & 1.5 & 1.6 \\
1.9 & 1.8 & 1.6 & 1.4 & 1.5 & 1.4 & 1.6 & 1.5 & 4.2 & 1.9 \\
2.0 & 1.8 & 1.6 & 1.5 & 1.6 & 1.5 & 1.8 & 1.6 & 1.9 & 4.4
\end{array}\right]
$$

The simulation results are presented in Table 4.

Table 1. Parameters of CSA AND ES-CSA[41].

\begin{tabular}{cccc}
\hline Algorithms/parameters & AP & fl & $\beta$ \\
\hline CSA & 0.2 & 2 & - \\
ES-CSA & 0.2 & 2 & 1.5 \\
\hline
\end{tabular}

Table 2. The Parameters of the Cost Function and Generators Limits of the 10 -Unit System

\begin{tabular}{|c|c|c|c|c|c|c|c|c|c|c|c|}
\hline Unit & $\begin{array}{c}P_{\max } \\
(\mathrm{MW})\end{array}$ & $\begin{array}{c}P_{\min } \\
(\mathrm{MW})\end{array}$ & $\mathrm{c}$ & $\mathrm{b}$ & $\mathrm{a}$ & $\mathrm{t}_{\mathrm{up}}(\mathrm{h})$ & $t_{\text {down }}(l$ & $\mathrm{S}_{\mathrm{hr}}(\mathrm{h})$ & $\mathrm{S}_{\mathrm{cr}}(\mathrm{h})$ & $t_{\text {cold }} 1$ & $\mathrm{i}_{\text {nit.st }}$ \\
\hline 1 & 55 & 10 & 1000 & 40.54 & 0.12951 & 8 & 8 & 4500 & 9000 & 5 & 8 \\
\hline 2 & 80 & 20 & 950 & 39.58 & 0.10908 & 8 & 8 & 5000 & 10,000 & 5 & 8 \\
\hline 3 & 120 & 47 & 900 & 36.51 & 0.12511 & 5 & 5 & 550 & 1100 & 4 & -5 \\
\hline 4 & 130 & 20 & 800 & 39.51 & 0.12111 & 5 & 5 & 560 & 1120 & 4 & -5 \\
\hline 5 & 160 & 50 & 756 & 38.53 & 0.15247 & 6 & 6 & 900 & 1800 & 4 & -6 \\
\hline 6 & 240 & 70 & 451 & 46.15 & 0.10587 & 3 & 3 & 170 & 340 & 2 & -3 \\
\hline 7 & 300 & 60 & 1243 & 38.30 & 0.03546 & 3 & 3 & 260 & 520 & 2 & -3 \\
\hline 8 & 340 & 70 & 1049 & 40.39 & 0.02803 & 1 & 1 & 30 & 60 & 0 & -1 \\
\hline 9 & 470 & 135 & 1658 & 36.32 & 0.02111 & 1 & 1 & 30 & 60 & 0 & -1 \\
\hline 10 & 470 & 150 & 1356 & 38.27 & 0.01799 & 1 & 1 & 30 & 60 & 0 & -1 \\
\hline
\end{tabular}

Table 3. Load Data for 10 Units, $24 \mathrm{~h}$

\begin{tabular}{cccccccc}
\hline Hour & Load (MW) & Hour & Load (MW) & Hour & Load (MW) & Hour & Load (MW) \\
\hline 1 & 700 & 7 & 1150 & 13 & 1400 & 19 & 1200 \\
2 & 750 & 8 & 1200 & 14 & 1300 & 20 & 1400 \\
3 & 850 & 9 & 1300 & 15 & 1200 & 21 & 1300 \\
4 & 950 & 10 & 1400 & 16 & 1050 & 22 & 1100 \\
5 & 1000 & 11 & 1450 & 17 & 1000 & 23 & 900 \\
6 & 1000 & 12 & 1500 & 18 & 1100 & 24 & 800 \\
\hline
\end{tabular}

Table 4. Results of the Economic Dispatching of 10-Unit System

\begin{tabular}{cccc}
\hline & CM & PSO & ESCSA \\
\hline P1 (MW) & 47.8749 & 47.9492 & 47.9392 \\
P2 (MW) & 62,1299 & 62,1460 & 61,1460 \\
P3 (MW) & 67.8696 & 67,8343 & 67,8343 \\
P4 (MW) & 58.8633 & 58.8639 & 58.9039 \\
P5 (MW) & 50 & 50 & 52 \\
P6 (MW) & 70 & 70 & 71 \\
P7 (MW) & 206.8056 & 206.7936 & 206.7936 \\
P8 (MW) & 224.5906 & 224.6132 & 224.7032 \\
P9 (MW) & 377.5342 & 377.4816 & 377.4816 \\
P10 (MW) & 383.4761 & 383.4313 & 383.4313 \\
PL (MW) & 49.1165 & 49.1148 & 49.1148 \\
Fuel cost & 81115 & 81115 & 81113.35 \\
(\$/h) & & & \\
\hline
\end{tabular}




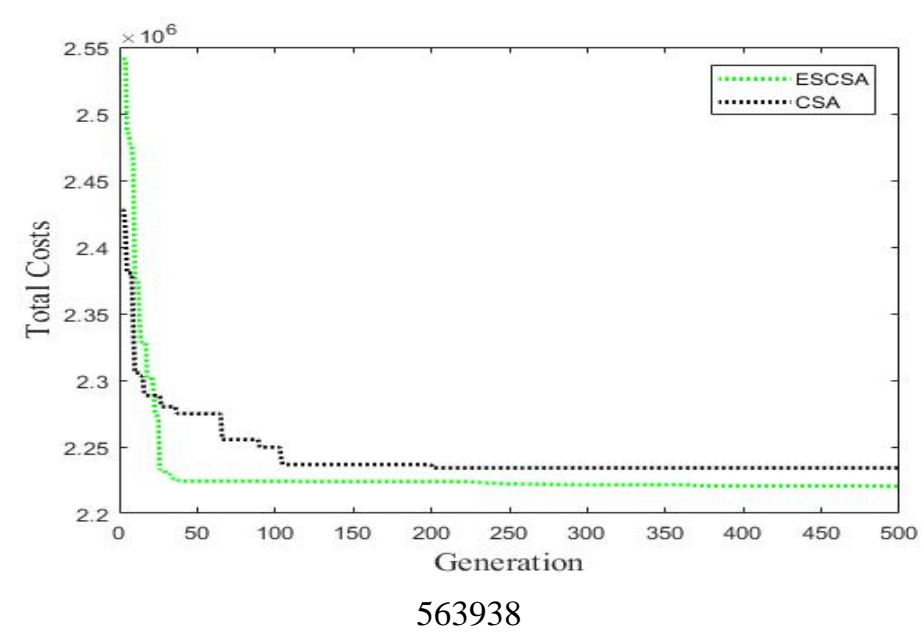

Figure 1. Convergence characteristic of fuel cost using Binary ES-CSA for 10-units based UC problem

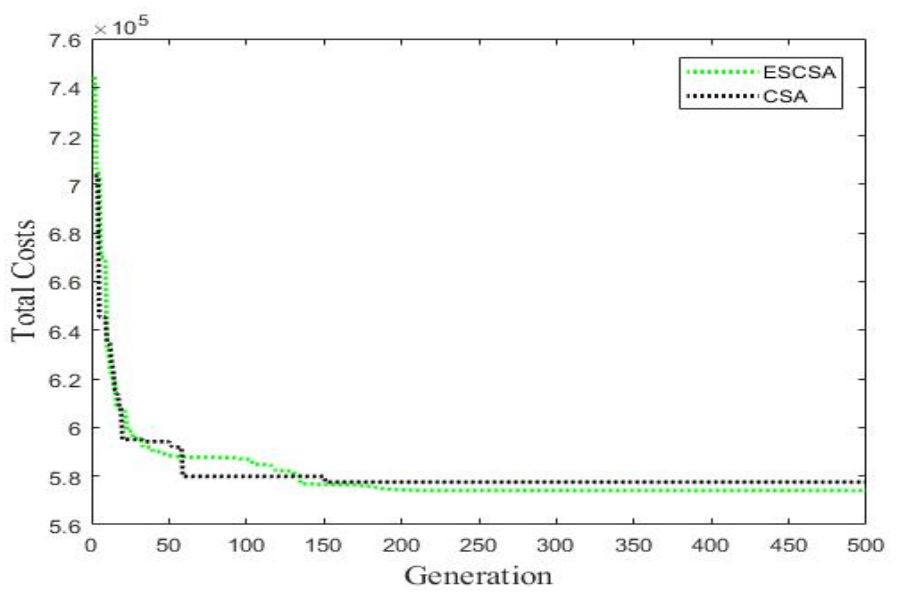

Figure 2. Convergence characteristic of fuel cost using Binary ES-CSA for 10-units based economic dispatch

\section{CONCLUSION}

In this paper, we proposed an eagle strategy based crow search algorithm (ES-CSA) to solve unit Economic dispatch and unit commitment problem in smart grid system. The practicality of the proposed metaheuristics ES-CSA was tested for 10 power generators test case. The gained results were compared to existing results based on PSO and CM methods. It was shown that ES-CSA are superior in obtaining a combination of power loads that fulfill the problem constraints and minimize the total fuel cost. ES-CSA found to be efficient in finding the optimal power generation loads. ES -CSA was capable of handling the non-linearity of ED problem And UC. The evolved power using ES-CSA minimized both the cost of generated power, the total power loss in the transmission and maximizes the reliability of the power provided to the customers. The programs were developed using MATLAB. The results have shown that our ES-CSA to give us a better performance with optimal results in all cases and respecting the constraints imposed.

\section{ACKNOWLEDGEMENTS}

The authors are very much thankful to the unanimous reviewers of the paper and editors of the journal for their constructive and helpful comments that improved the quality of the paper.

\section{REFERENCES}

[1] C.He-Rui, P. Xu, "Study on Smart Grid System Based on System Dynamics", TELKOMNIKA Indonesian Journal of Electrical Engineering Vol. 12, No. 12, pp. 7979-7986, December 2014. 
[2] Shahinzadeh H, Hasanalizadeh-Khosroshahi A. "Implementation of Smart Metering Systems: Challenges and Solutions". TELKOMNIKA Indonesian Journal of Electrical Engineering. 2014; 12(7).

[3] Ajenikoko GA, Olabode OE. Optimal Power Flow with Reactive Power Compensation for Cost and Loss Minimization on Nigerian Power Grid System. Indonesian Journal of Electrical Engineering and Informatics. 2017; 5(3): 236-247.

[4] A. J. Wood and B. F. Wollenberg, Power generation, operation, and control. John Wiley \& Sons, 2012.

[5] Hermagasantos Z, Yusra S, Ali M. Implementation of Electricity Competition Framework with Economic Dispatch Direct Method. TELKOMNIKA Indonesian Journal of Electrical Engineering. 2012; 10(4): 667-674.

[6] Wollenberg B, Wood A (1996) Power generation, operation and control. Wiley, New York.

[7] Dieu VN, Schegner P, Ongsakul W (2013) Pseudo-gradient based particle swarm optimization method for nonconvex economic dispatch. In: Power, control and optimization. Springer, New York, pp 1-27.

[8] Muhtazaruddin, M.N.B., Bani, N.A., Aris, S.A.M., Kaidi, H.M., Fatah, A.Y.A., Jamia, J.J., Muhammad-Sukki, F. and Abu-Bakar, S.H. "Distribution power loss minimization via distributed generation, capacitor and network reconfiguration”. Indonesian Journal of Electrical Engineering and Computer Science. 2017; 5(3): 488-495.

[9] Arriffin, A.M., Othman, M.M., Kamaruzaman, A.A.M., Musirin, I., Yahya, A., \& Latip, M.F.A. "Stochastic Approach of Voltage Optimization to Maximize Power Saving in a Building". Indonesian Journal of Electrical Engineering and Computer Science. 2017; 8(1): 268-272.

[10] Moradi-Dalvand M., B. Mohammadi-Ivatloo, A. Najafi, A. Rabiee. Continuous quick group search optimizer for solving non-convex economic dispatch problems. Electric Power Systems Research. 2012, Vol 93, pp. 93-105.

[11] L. Kirchmayer, Economic Operation of Power Systems. New Delhi: Wiley Eastern Limited, first ed.,1979.

[12] A. J. Wood and B. F. Wollenberg, Power Generation Operation and Control. New York: John Wiley \& Sons, Inc., second ed., 2006.

[13] G. F. Reid and L. Hasdorff, "Economic dispatch using quadratic programming," IEEE Transactions on Power Apparatus and Systems, vol. PAS-92, no. 6, pp. 2015-2023, Nov 1973.

[14] K. Aoki and T. Satoh, "New algorithms for classic economic load dispatch," IEEE Transactions on Power Apparatus and Systems, vol. PAS-103, no. 6, pp. 1423-1431, June 1984.

[15] J. K. Delson and S. M. Shahidehpour, "Linear programming applications to power system economics, planning and operations," IEEE Transactions on Power Systems, vol. 7, no. 3, pp. 1155-1163, Aug 1992.

[16] S. Subramanian and S. Ganesan, "A simple approach for emission constrained economic dispatch problems," International Journal of Computer Applications, vol. 8, no. 11, pp. 39-45, October 2010, published By Foundation of Computer Science.

[17] D. D. Obioma and A. M. Izuchukwu, "Comparative analysis of techniques for economic dispatch of generated power with modified lambda-iteration method," in Proceedings of the 2013 IEEE International Conference on Emerging Sustainable Technologies for Power ICT in a Developing Society (NIGERCON), Nov 2013, pp. 231-237.

[18] S. K. Mishra and S. K. Mishra, "A comparative study of solution of economic load dispatch problem in power systems in the environmental perspective," Procedia Computer Science, vol. 48, pp. $96-100,2015$.

[19] Z. L. Gaing, "Particle swarm optimization to solving the economic dispatch considering the generator constraints," IEEE Transactions on Power Systems, vol. 18, pp. 1187-1195, 2003.

[20] H. Faris, A. Sheta, and E. "Oznergiz, "Modelling hot rolling manufacturing process using soft computing techniques," International Journal of Computer Integrated Manufacturing, vol. 26, no. 8, pp. 762-771, 2013.

[21] A. F. Sheta, H. Faris, and E. "Oznergiz, "Improving production quality of a hot-rolling industrial process via genetic programming model," Int. J. Comput. Appl. Technol., vol. 49, no. 3/4, pp. 239-250, Jun. 2014.

[22] H. Faris and A. F. Sheta, "A comparison between parametric and non-parametric soft computing approaches to model the temperature of a metal cutting tool," International Journal of Computer Integrated Manufacturing, vol. 29, no. 1, pp. 64-75, 2016.

[23] M. Braik, A. Sheta, and A. Ayesh, "Particle swarm optimization enhancement approach for improving image quality," Int. J. Innov. Comput. Appl., vol. 1, no. 2, pp. 138-145, Jan. 2007.

[24] B. Solaiman and A. Sheta, "Evolving a hybrid KMeans clustering algorithm for wireless sensor network using PSO and GA," International Journal of Computer Science Issues, vol. 12, no. 1, pp. 23-32, 2015.

[25] J. Sasikala and R. M, "Optimal _ based economic emission dispatch using simulated annealing," International Journal of Computer Applications, vol. 1, no. 10, pp. 55-63, February 2010, published By Foundation of Computer Science.

[26] H. Hardiansyah, "Artificial bee colony algorithm for economic load dispatch problem," IAES International Journal of Artificial Intelligence, vol. 2, no. 2, pp. 90-98, 2013.

[27] W.M. Aly and A. Sheta, "Parameter estimation of nonlinear systems using l'evy flight cuckoo search," in Proceedings of the Thirty-third SGAI International Conference on Innovative Techniques and Applications of Artificial Intelligence, Cambridge, England, UK, 2013, pp. 443-449.

[28] "Comparative analysis of optimal load dispatch through evolutionary algorithms," Ain Shams Engineering Journal, vol. 6, no. 1, pp. 107-120, 2015.

[29] R. Habachi et al. Resolution of Economic Dispatch Problem of the moroccan Network Using Crow Search Algorithm. Indonesian Journal of Electrical Engineering and Computer Science Vol. 13, No. 1,janvier 2019.

[30] Aruldoss T., Victoire A.A., Jeyakumar E., 2005. A modified hybrid EP-SQP approach for dynamic dispatch with valve-point effect, International Journal of Electrical Power \& Energy Systems. Vol. 7, pp. 594-601. 
[31] (Surekha, 2012). Surekha P, N. Archana, S. Sumathi. June 2012. Solving unit commitment and economic load dispatch problems using ga and pso algorithms. International Journal of Computer Science and Information Engineering, Vol. 3, No. 1, pp. 7-21.

[32] X.-S. Yang and S. Deb, "Eagle strategy using levy' walk and firefly algorithms for stochastic optimization," in Nature Inspired Cooperative Strategies for Optimization (NICSO 2010). Springer, 2010, pp. 101- 111.

[33] A. Askarzadeh, "A novel metaheuristic method for solving constrained engineering optimization problems: crow search algorithm," Computers \& Structures, vol. 169, pp. 1-12, 2016.

[34] A. Askarzadeh, "Electrical power generation by an optimised au-tonomous pv/wind/tidal/battery system," IET Renewable Power Generation, 2016.

[35] D. Oliva, S. Hinojosa, E. Cuevas, G. Pajares, O. Avalos, and J. Galvez,' "Cross entropy based thresholding for magnetic resonance brain images using crow search algorithm," Expert Systems with Applications, vol. 79, pp. 164-180, 2017.

[36] A. J. Wood and B. F. Wollenberg, Power generation, operation, and control. John Wiley \& Sons, 2012.

[37] D. Oliva, S. Hinojosa, E. Cuevas, G. Pajares, O. Avalos, and J. Galvez,' "Cross entropy based thresholding for magnetic resonance brain images using crow search algorithm," Expert Systems with Applications, vol. 79, pp. 164-180, 2017.

[38] X. Yuan, A. Su, H. Nie, Y. Yuan, and L. Wang, "Unit commitment problem using enhanced particle swarm optimization algorithm," Soft Computing-A Fusion of Foundations, Methodologies and Applications, vol. 15, no. 1, pp. 139-148, 2011.

[39] A. L. Devi and O. V. Krishna, "Combined economic and emission dispatch using evolutionary algorithms: A case study," ARPN Journal of Engineering and Applied Sciences, vol. 3, no. 6, pp. 28-35, 2008.

[40] GAING, Z. L. Particle Swarm Optimization to Solving the Economic Dispatch Considering the Generator Constraints. IEEE transactions on power systems, 2003, vol. 18 (3), pp. 1187-1195.

[41] R. Habachi et al. Eagle Strategy Based Crow Search Algorithm for Solving Unit Commitment Problem in Smart Grid System, Indonesian Journal of Electrical Engineering and Computer Science Vol. 12, No. 1, pp. 17 29 October 2018. 